\title{
Characterization of Retained Austenite and Carbides in Stainless Steel by Combined EBSD, EDS, and XRD
}

\author{
C. M. Parish*, T. R. Watkins*, O. Rios, ${ }^{*}$ G. Mackiewicz- Ludtka, ${ }^{*}$ G. M. Ludtka, ${ }^{*}$ O.B. Cavin** \\ * Materials Science and Technology Division, Oak Ridge National Laboratory, Oak Ridge, TN \\ 37831-6064 \\ ** University of Tennessee, Knoxville, TN 37996-0750
}

Retained austenite (RA) in steels has a significant effect on the mechanical properties. Measurement of the fraction, grain size, and crystallographic texture of the ferritic (or martensitic) matrix, the RA, and carbides (if present), is essential to understanding a steel's processing-properties relationships. Electron backscatter diffraction (EBSD) is a good approach for RA measurement, but RA-containing steels are a difficult problem because the cubic phases give similar EBSD patterns [1]. In this work, a thermomagnetically processed $\mathrm{Fe}-13.0 \mathrm{Cr}-0.7 \mathrm{Mn}-0.4 \mathrm{Si}-0.68 \mathrm{C}$ (nominal wt $\%$ ) steel (hot-rolled thin strip) was found via X-Ray Diffraction (XRD) to contain a ferritic/martensitic matrix, RA, and $\mathrm{M}_{23} \mathrm{C}_{6}$ carbides. However, overlapping XRD peaks and strong texture made it difficult to precisely determine the RA volume fraction, which is a vital metric to compare processing paths.

EBSD was performed on colloidal silica polished material in a JEOL6500F SEM with an EDAX Hikari system over a $30 \times 30 \mu \mathrm{m}$ area with $100 \mathrm{~nm}$ steps and a $10 \mathrm{kV}, 3.0 \mathrm{nA}$ probe. Figs. 1a, 1b, and 1c show the SEM image, the phase map, and the confidence index (CI), respectively. Clearly, the phase map in Fig. $1 \mathrm{~b}$ is meaningless, with both ferrite and $\mathrm{M}_{23} \mathrm{C}_{6}$ giving 45 area\% each, and the CIs in 1c are poor ("ferrite" here refers to BCC ferrite and BCT martensite phases - the martensite tetragonality was insufficient to index). Since all three phases are cubic, the EBSD patterns are similar and the EBSD algorithm is unable to find unique solutions despite using a large number of Hough peaks (12-15) for indexing. The phase map was acquired simultaneously with elemental maps via EDS. Fig. 2a shows an image quality (IQ) map, and Figs. $2 \mathrm{~b}$ and $2 \mathrm{c}$ show the Fe and $\mathrm{Cr} \mathrm{X}$ ray maps, respectively. Fig. $2 \mathrm{~d}$ shows a red-blue-yellow-magenta map of four partitions identified by statistical analysis using EDAX OIM software of the $\mathrm{Cr}$, Fe, and IQ maps. The Hough peaks were re-indexed offline with the red partition restricted to ferrite+austenite, yellow to austenite $+\mathrm{M}_{23} \mathrm{C}_{6}$, and blue and magenta to $\mathrm{M}_{23} \mathrm{C}_{6}, \mathrm{M}_{7} \mathrm{C}_{3}$ and $\mathrm{Fe}_{3} \mathrm{C}$, respectively. Figs. $3 \mathrm{a}$ and $3 \mathrm{~b}$ show the re-indexed phase map and the CI map, respectively. From the re-indexed data, the RA is $\sim 7.1$ area\%, a qualitatively reasonable number and $\mathrm{M}_{7} \mathrm{C}_{3}$ and $\mathrm{Fe}_{3} \mathrm{C}$ are both $\sim 1$ area\%, indicating they are not likely present but are simply mis-indexing artifacts. Clearly, the indexing in Fig. 3a is more consistent and the confidence (3b) is higher compared to Fig. 1. Although some problems should be resolved before concluding that the re-indexed data are fully "corrected," combining EDS and EBSD is certainly a reasonable approach for the problems of cubic carbides in a matrix of ferrite/martensite and austenite. Problems to still be addressed are surface relief from sample preparation (resulting in lowered IQ near harder phases) and the intrinsically different spatial resolution in EBSD and EDS signal generation [2].

[1] G. Thomas et al., Microsc. Microanal. (2011) in press.

[2] Research sponsored by ORNL's Shared Research Equipment (SHaRE) User Facility, which is sponsored by the Office of Basic Energy Sciences, U.S. Department of Energy, and by the U.S. Department of Energy, Office of Energy Efficiency and Renewable Energy, Industrial Technologies Program, under contract DE-AC05-00OR22725 with UT-Battelle, LLC. 

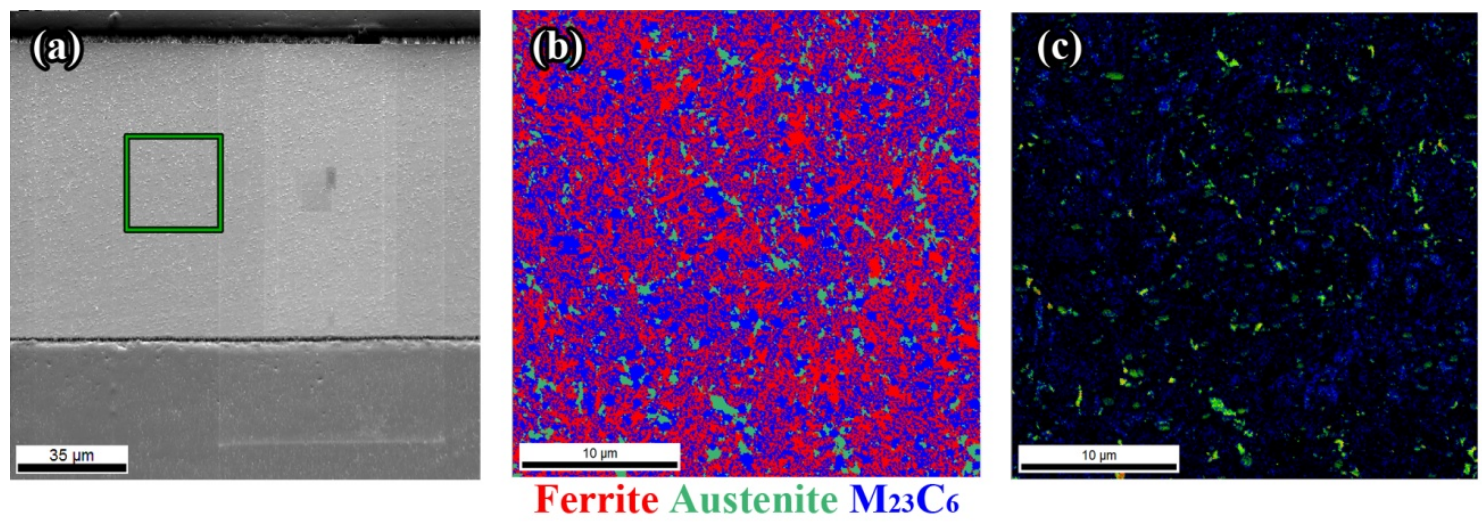

FIG. 1. (a) SEM image of polished sample - box indicates $30 \times 30 \mu \mathrm{m}$ EBSD scan area, (b) EBSD phase map not including chemical information, and (c) Confidence Index map not including chemical information.
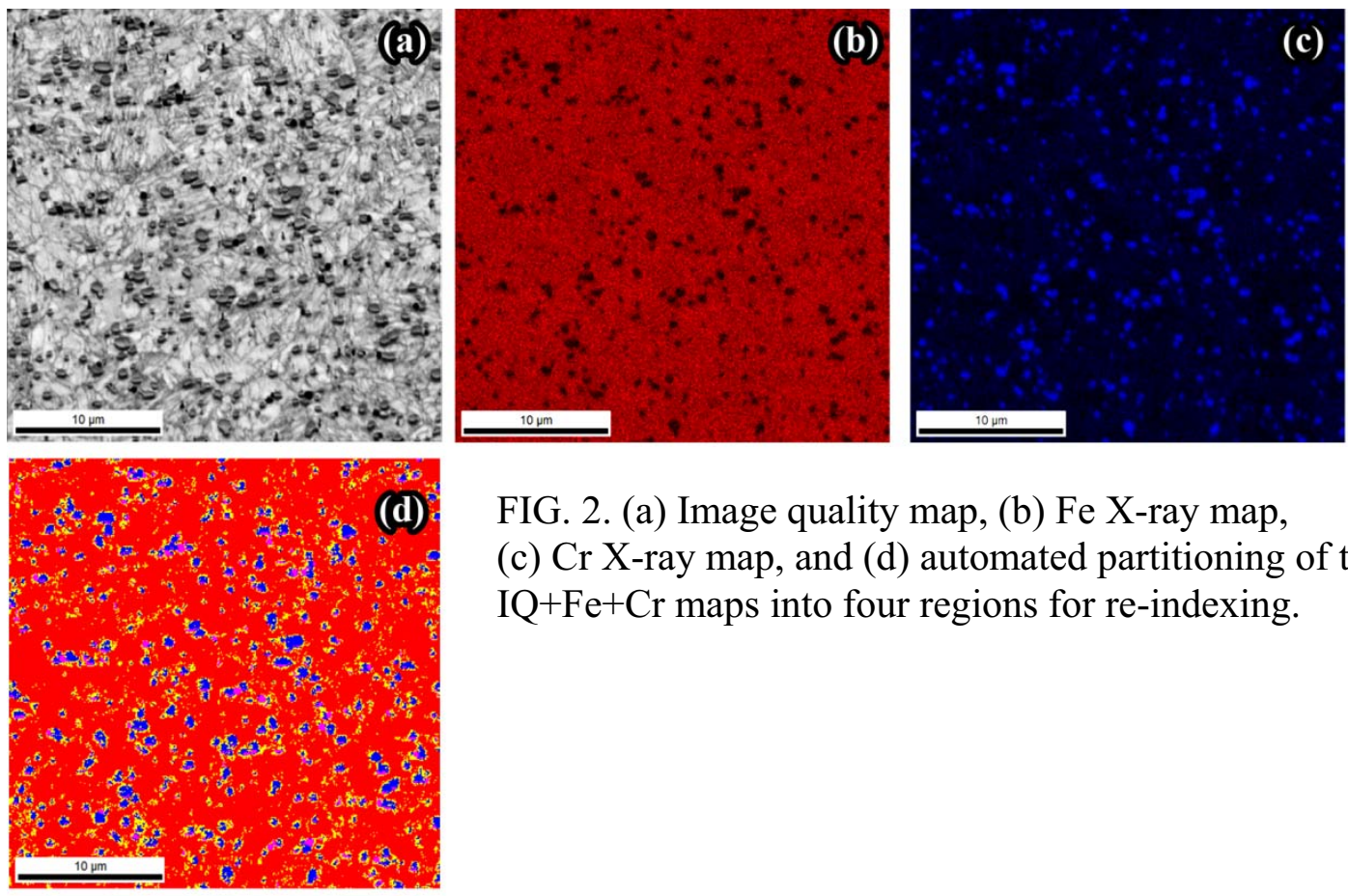

FIG. 2. (a) Image quality map, (b) Fe X-ray map,

(c) Cr X-ray map, and (d) automated partitioning of the $\mathrm{IQ}+\mathrm{Fe}+\mathrm{Cr}$ maps into four regions for re-indexing.

Figure 3: (a) Re-indexed phase map using chemical information. (b) Confidence index map using chemical information.

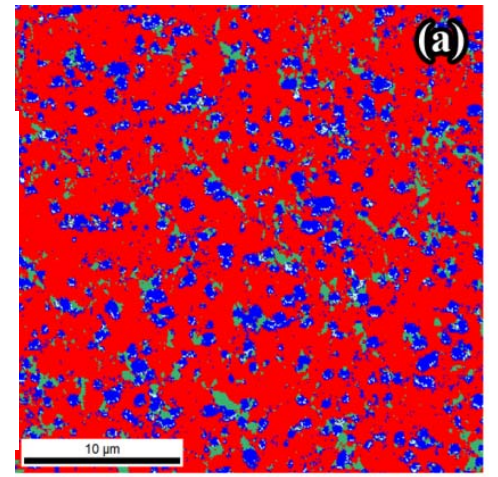

Ferrite Austenite $\mathrm{M}_{23} \mathrm{C}_{6} \mathrm{M}_{7} \mathrm{C}_{3} \mathrm{Fe}_{3} \mathrm{C}$

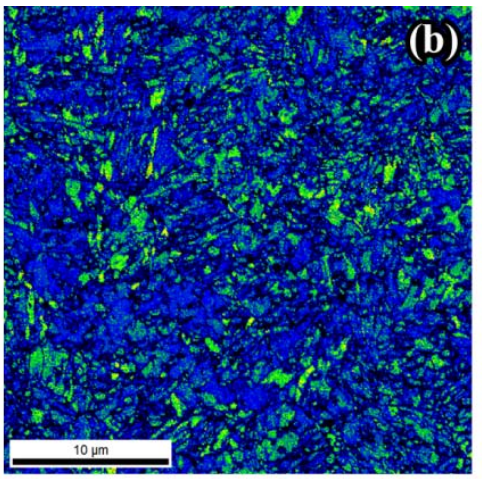

